$\mathbb{P}$ periodica polytechnica

Civil Engineering

$54 / 2(2010) 117,126$

doi: 10.3311/pp.ci.2010-2.07

web: http://www.pp.bme.hu/ci

(c) Periodica Polytechnica 2010

RESEARCH ARTICLE

\section{Temperature dependent flexural stiffness of load bearing laminated glass panes}

\author{
Kinga Pankhardt
}

Received 2009-12-17, revised 2010-05-26, accepted 2010-06-23

\begin{abstract}
Load bearing glasses are used not only in interior but also in exterior applications. The flexural stiffness of laminated glass is influenced by temperature. With increasing temperature the shear stiffness rapidly decreases and creep becomes more significant (Krüger, 1998). According to Wölfel's (1987) calculations, the shear modulus of the interlayer material has the most influence on the strength and deflection. In the case of thin or large size glasses, where the deformations (deflections) are considerable, temperature dependent flexural stiffness of the overall laminate is more significant. This paper deals with the influence of temperature on flexural stiffness of laminated glasses. Based on the laboratory results, the Author modified the definition of the coupling parameter, which represents the bond of the glass layers by the interlayer and was originally defined by Krïger (1998).
\end{abstract}

\section{Keywords \\ glass $\cdot$ laminated glass $\cdot$ flexural stiffness $\cdot$ EVA $\cdot$ resin}

\section{Acknowledgement}

The author would like to express thanks to Prof. Gy. $L$. BALÁZS for the support and guidance throughout her PhD work. The author would like to express thanks to Rákosy GLASS Ltd. for providing the specimens and for the support to DSC analysis of plastics to Prof. Dr. V. Vargha and R. C. Bende, Sz. Máté, BME Department of Plastics and Rubber Technology. The authors would like to thank to Dr. S. G. Nehme for his intellectual support and would also like to thank to Dr. S. Fehérvári, A. Eipl, M. Varga, D. Diriczi, G. Kovács and P. Tisza for their technical support at Department of Construction Materials and Engineering Geology, BME.

\section{Kinga Pankhardt}

Department of Civil Engineering, Debrecen University, H-4028 Debrecen, Hungary

e-mail: kpankhardt@yahoo.com

\section{Introduction}

The discovery of glass lamination happened accidentally. While Benedictus (1910) heated a solution of nitrocellulose and accidentally dropped it on a glass pane, he found that when the glass fractured it did not shatter. Benedictus patented (British Patent 1.790) laminated glass in 1910. The production of laminated glass started in 1912 in Great Britain.

Nowadays laminated glass consists of two or more glass layers with one or more plastic layers between the glass panes. Joining of the glass layers with foil can take place in a pressurised vessel, called an autoclave. In the autoclave, under simultaneous heating of the already processed layers of glass and special plastic, lamination occurs. In the case of cast in place process, liquid resin is cast between two sheets of glass layers and then the liquid resin is polymerised with UV radiation or by catalysis. As the resin is liquid, it perfectly fills the space between the glass layers, hence it is ideal for use with imperfectly smooth glass surfaces, such as tempered and textured glass or non-parallel sheets, such as bent glass. Therefore, the cast in place process is mostly used for non-standard dimensions of laminated glass.

When laminated glass began to be used in significant quantities for the architectural glazing industry in the 1960s, building codes defined a strength factor of 0.6 relative to monolithic single glass of the same thickness [3]. The basis to define this factor numerically is unclear, although in bending tests the load bearing capacity $\left(F_{\max }\right)$ of a layered two-ply laminate without an interlayer is 0.5 times a monolithic pane of the same thickness [4]. Nowadays, there is a general consensus to increase the glass strength factor. Strength factor $S F$ of laminated glass is defined by Eq. (1):

$$
S F=\frac{\text { maximal resisting force of laminated glass }}{\text { maximal resisting force of monolithic single glass }}
$$

The interlayer has two functions: (i) to keep in place the glass splinters during the fracture process of a glass pane to reduce the risk of injury and (ii) to increase residual load bearing capacity (Fig. 1). Fig. 1]indicates a fractured overhead glazing of a store 
in Vienna. The multilayer laminated glass remained in position even after fracturing and did not fall onto the pedestrian.

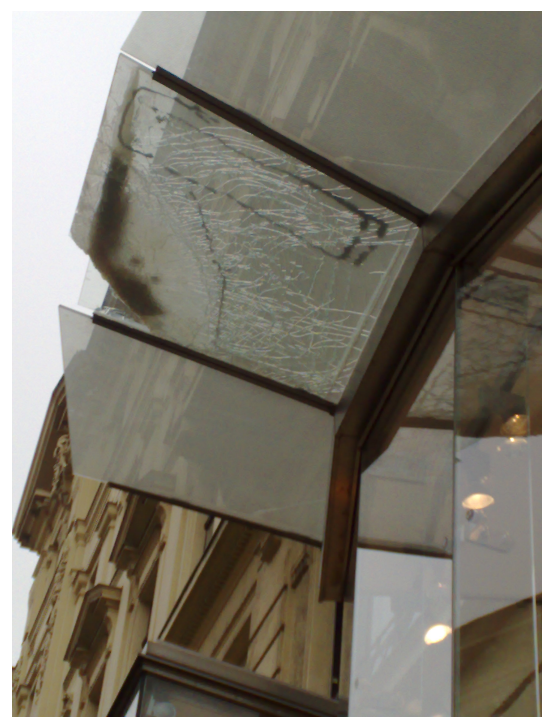

Fig. 1. Fractured overhead glazing, Humanic store, Vienna, 2007.

Depending on the shear stiffness and thickness of the interlayer, the laminate can exceed the strength of the equivalent monolith glass having the same total glass thickness. However, this effect is only valid as long as the interlayer material remains stiff. The strength of laminated glass is influenced by the strength of the glass layers and the shear transfer of the interlayer. Without appropriate shear transfer capacity, the interlayer functions as a spacer between the glass layers, therefore, it can increase the moment of inertia of the overall laminate, but can not decrease the deflections efficiently.

Increase of temperature results in a decrease of the stiffness of the laminate, which also affects the strength factor.

The strength in the glass panes is influenced by the shear transfer of the interlayer [1]. When the bond is efficient and the strain of the interlayer is small, the composite behaves almost monolithic (Fig. 2).

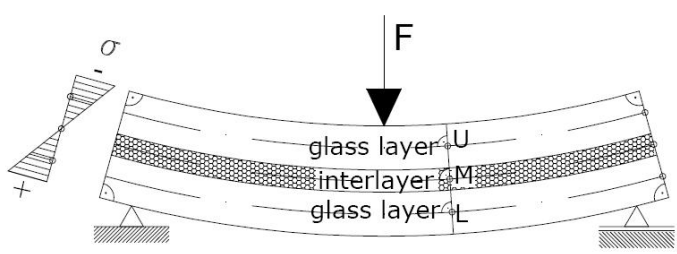

Fig. 2. Rigidly bonded glass layers. (The figure is non proportional in transverse direction.)

In the case of the so-called "rigid bond", the load bearing capacity of laminated glass having same thickness compared to a single layer glass can be over-estimated [4].

Norville (1997) [5] published experimental strength data on laminated glass specimens manufactured with a $2.28 \mathrm{~mm}$ polyvinyl butyral interlayer which exceeded the strength of laminated glass specimens having the same dimensions but which used a $0.76 \mathrm{~mm}$ thick interlayer, as well as the strength of monolithic glass samples having a comparable thickness (Fig. 3 ).

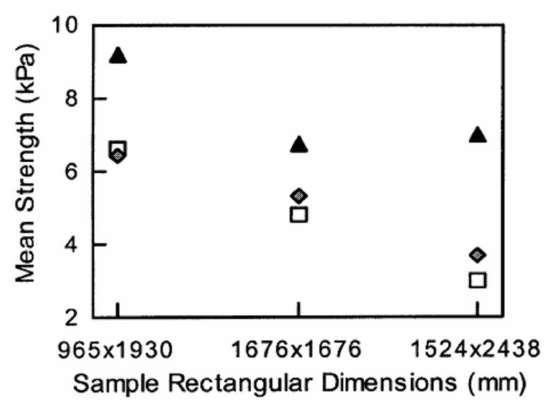

Fig. 3. Results of bending tests under uniform loading at room temperatures, where specimens were supported along two edges. Squares indicate monolithic specimens with thickness of $6 \mathrm{~mm}$, diamonds: two glass layers with thickness of $3 \mathrm{~mm}$ laminated with $0.76 \mathrm{~mm}$ PVB interlayer, triangles: specimens laminated with $2.28 \mathrm{~mm}$ of PVB interlayer thickness [5].

The load bearing capacity of laminated glass can be increased with increase of thickness of interlayer material in the case of appropriate bond. Research results of [5-7] indicated that with increase of PVB interlayer thickness the load bearing capacity of laminated glass increases at room temperature.

Fig. 3 indicates also that with an increase of the area and (or) number of glass layers, therefore, the increase of number of defects on the glass surface, affects the load bearing capacity of the laminate. In the case of relatively large glass layer area, the strength is considerably influenced by the size effect. The reason for the size effect is the stochastic distribution of the defects in the glass pane (Weibull type size effect, otherwise called statistical size effect) [8].

The flexural stiffness of laminated glass is influenced by temperature. With increasing temperature the shear stiffness rapidly decreases and creep [2] becomes more significant, therefore, the effect of temperature should be studied. To study the behaviour of the laminated glass, it is important to know the physical properties of glass layers and also the physical and chemical properties of commonly used interlayer materials. The temperature [9] and the rate of loading [10,11] influence the properties of the polymers which will affect also the behaviour of laminate.

The main phase transition temperature of polymers is the glass transition temperature, $T_{g}$. At this temperature, the amorphous polymer or the amorphous component of the semicrystalline polymer changes from a glassy state to a rubbery state and the material softens considerably. Beyond this temperature, the purely amorphous polymer does not show further transition and the material is in a liquid state. However, a semicrystalline polymer exhibits another transition at a higher temperature than the glass transition temperature. This is the melting temperature, $T_{m}$. (Note that there is no melting behaviour in the amorphous polymer.) Physical and mechanical properties of polymers (including thermal expansion coefficient, heat capacity and refractive index) will change at the glass transition temperature, $T_{g}[12]$. 

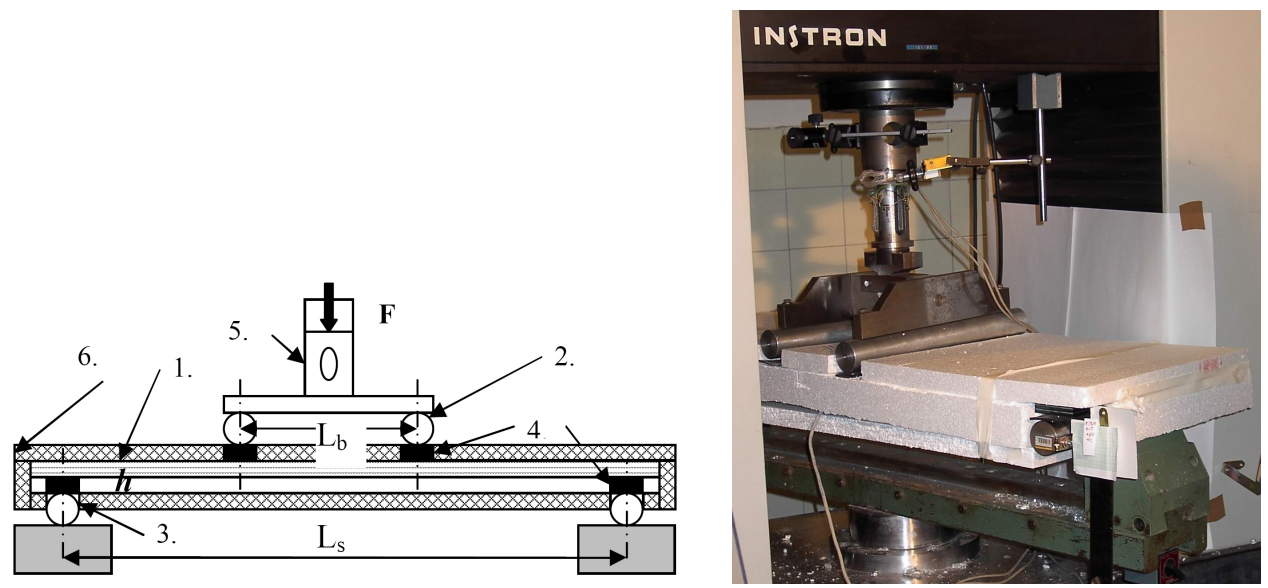

Fig. 4. Test method for four-point bending $[13]$ where, 1 . specimen $1100 \times 360 \mathrm{~mm}, 2$. bending roller, 3 . supporting roller, 4. rubber strips ( $3 \mathrm{~mm}$ thick, according to ISO $48[\overline{14} \mid)$, 5. self-designed transducer, 6 . custom-made

\section{Materials and experimental procedure}

The effect of temperature of $-20{ }^{\circ} \mathrm{C},+23{ }^{\circ} \mathrm{C}$ and $+60{ }^{\circ} \mathrm{C}$ were investigated on bending characteristics of laminated glasses.

\subsection{Test parameters and test programme}

Specimens were manufactured from soda-lime silicate float glass. All glass specimens with a constant span of $L_{s}=1000 \mathrm{~mm}$ and supported at a width of $b=360 \mathrm{~mm}$ were tested in fourpoint bending. Test parameters of laminated glass specimens were the following [4]:

- Constants: test arrangement, width and length, thickness, rate of loading ( $20 \mathrm{~mm} / \mathrm{min})$, edgework.

- Variables: number of glass layers: two or three, type of laminate (non safety or safety laminate), type of interlayer material (resin or EVA foil or without interlayer), temperature of specimens.

Tests were based on glass panes with a thickness of $6 \mathrm{~mm}$. The chosen thickness allows the study of large deflections of the glass specimens in bending. Single glass specimens with thickness of 12 and $19 \mathrm{~mm}$ were also investigated, to compare the monolithic upper layered limit of $2 \times 6 \mathrm{~mm}$ and of $3 \times 6 \mathrm{~mm}$ laminated glass specimens. To determine the lower layered limit, laminated glasses layers without use of interlayer material (with use of only spacer at the edges) were tested. The schematic diagram of the test programme for laminated glass specimens is illustrated in [9].

Interlayer materials used in laminated glasses were resin (cast in place) and EVA (ethyl-vinyl-acetate) foil. While PVB (polyvinyl-butyral) foil is widely used in laminated glass, EVA foil is a new generation of foils. The main properties of the tested interlayer materials in more details are summarised in [4].

\subsection{Experimental procedure}

\subsubsection{Force measurements}

The test procedure was a semi-dynamic short-term test. The tests were carried out at a specimen temperature of $+23{ }^{\circ} \mathrm{C}$. Fur- insulation (40 mm thick), $L_{s}: 1000 \mathrm{~mm}, L_{b}: 200 \mathrm{~mm}$, h: thickness of the specimen $(6 \mathrm{~mm}, 12 \mathrm{~mm}, 19 \mathrm{~mm}$ or $2 \times 6,3 \times 6 \mathrm{~mm})$

ther specimens were heated to $+60{ }^{\circ} \mathrm{C}$ or cooled to $-20{ }^{\circ} \mathrm{C}$. The temperature of the specimens and the room temperature were continuously measured during the tests. The specimens were mounted as shown in Fig. 4 (a) and (b). The deflection at midspan of the glass panes were measured with displacement transducer in all tests.

The temperature was kept constant during the test with $1{ }^{\circ} \mathrm{C}$ in order to avoid the development of thermal stresses. The temperature of insulated specimens was measured on their surface during tests. Load was measured with a self-designed force transducer, developed by the authors [15] for Instron Type 1197 testing instrument. Values measured during the tests were simultaneously recorded by computer. The fracture process and crack pattern of glass specimens were recorded with digital optical methods. The specimens were tested until fracture (Figs. 5 and 6).

The average values were determined for each test combination from at least three measurements in the case of laminated glasses and four measurements in the case of single glasses.

\subsubsection{Differential scanning calorimetric analysis (DSC)}

The glass transition temperature, $T_{g}$, and melting temperature ranges, $T_{m}$, were not available for cured resin. These data were only available for EVA foil $\left(T_{g}\right.$ is $-28{ }^{\circ} \mathrm{C}$ and $T_{m}$ is +76 to $79{ }^{\circ} \mathrm{C}$ ). In order to determine the glass transition- and melting temperature ranges, DSC (Differential Scanning Calorimetric) tests were carried out at Faculty of Chemical Technology and Biotechnology, Department of Plastics and Rubber Technology, BME.

Type of used resin was: unsaturated polyester resin based on ortho-phthalic acid with stryrol content, pre-accelerated, light stabilised. Liquid resin and activator (ketoneperoxide) were mixed to create specimens for DSC analysis. DSC tests started at least 24 hours after mixing (end of cure time). The cured resin was highly flexible at room temperature. The dynamic DSC thermographs of the cured resin were available with the use of Perkin Elmer DSC 7 equipment. A $5 \mathrm{mg}$ sample was 
tested between temperatures from -60 to $220{ }^{\circ} \mathrm{C}$ in a nitrogenous area with a flow rate of $40 \mathrm{ml} / \mathrm{min}$. The rate of heating was $10{ }^{\circ} \mathrm{C} / \mathrm{min}$. Heat flow vs. temperature diagrams of the cured resin indicated that the glass transition temperature, $T_{g}$, is about $-38{ }^{\circ} \mathrm{C}$ and melting temperature, $T_{m}$, is $+109^{\circ} \mathrm{C}$ (between $80{ }^{\circ} \mathrm{C}$ and $140{ }^{\circ} \mathrm{C}$ ).

\section{Test results and discussions}

3.1 Strength factor of laminated glasses at different temperatures

Strength factor $(S F)$ of laminated glass can be calculated with use of Eq. (1) and can be indicated also with the ratio of maximal force of laminated glass to single glass layer with equivalent thickness. In case of laminated glass consisting of two or three glass layers with $6 \mathrm{~mm}$ thickness, the available single glass layers with equivalent thicknesses are $12 \mathrm{~mm}$ or $19 \mathrm{~mm}$. The experimental results showed that the behaviour of laminated glass is influenced by the temperature both for non heat-treated laminated glass and for tempered laminated glass. Fig. 7 indicates that this ratio significantly decreases with an increase of temperature in the case of laminated glass with resin interlayer material. Therefore, it is not preferred to increase this ratio or the strength factor - which is a consensus nowadays, as mentioned before - without specifying the exposure class on different types of laminated glasses. The effect of temperature on load bearing capacity and on deflections, especially in the case of load bearing laminated glasses, should not be neglected [4].

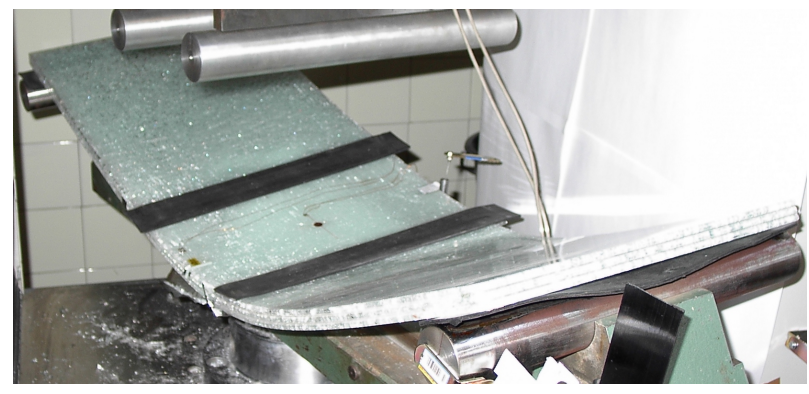

Fig. 5. Test of laminated safety glass specimen.

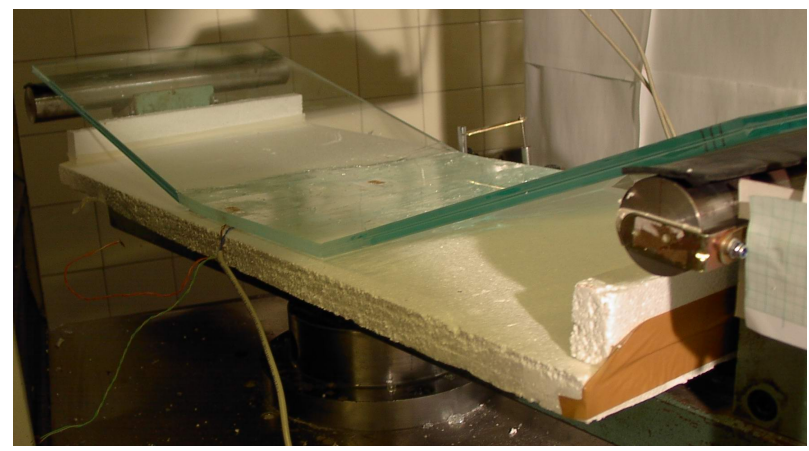

Fig. 6. Test of non safety laminated glass specimen.

At low temperatures $\left(-20{ }^{\circ} \mathrm{C}\right)$, the ratio significantly exceeds 1 , indicating that the interlayer material acts in flexure. At high temperatures $\left(+60{ }^{\circ} \mathrm{C}\right)$, the ratio remains significantly larger than 0 , indicating that the interlayer material maintains the ability to transfer horizontal shear force. Generally, this ratio lies between 0 and 1. Fig. 7 also indicated that in the case of resin interlayer material the strength factor more decreases with increase of temperature from room temperature to $+60{ }^{\circ} \mathrm{C}$ than in the case of EVA foil. At lower temperature the resin interlayer behaves rigidly, therefore the strength factor increases, while it decreases in the case of EVA foil. Reason for that is that bonding between the resin and the glass (chemical bond) is extremely strong because of the chemical link between the resin and the silol $(\mathrm{SiOH})$ groups on the glass surface. These chemical bonds which are formed during and after curing are highly stable and resistant. Laminates with use of resin interlayer sometimes offer better humidity resistance than foil-laminated glasses [16].

Figs. 8 (a) to (d) illustrate the quantitative change of ultimate force and deflection with change of temperature of laminated glasses with EVA interlayer material, compared to $+23{ }^{\circ} \mathrm{C}$ in percent. Figs. 9 (a) to (d) illustrate the quantitative change of ultimate force and deflection with change of temperature of laminated glasses with resin interlayer material, compared to $+23{ }^{\circ} \mathrm{C}$ in percent. Values for laminated glass with non-bonded layers at $+23{ }^{\circ} \mathrm{C}$ were also illustrated. The ratio of standard deviation and the average (value of ultimate force or deflection) of tested laminated glasses are indicated on the top of the columns in Figs.

In case of tempered glass layers the effect of temperature on bending characteristics can be better shown. In case of float glass the so-called critical crack in glass influences mainly the bearing capacity of the laminate. In case of EVA interlayer indicate that with increase of temperature from $+23{ }^{\circ} \mathrm{C}$ to $+60{ }^{\circ} \mathrm{C}$ the increase of ultimate Figs. 8 (b) and (d) deflection is higher than the decrease of the ultimate force of laminated glass. In all tested types of laminated glass can be indicated that the ultimate deflection is more influenced by change of temperature than the ultimate force. In case of resin interlayer, linear curve can be fitted with the best correlation for the decrease of ultimate force by increase of temperature from $-20{ }^{\circ} \mathrm{C}$ to $+60{ }^{\circ} \mathrm{C}$. With increase of temperature of resin laminated glass, the interlayer softens considerably. Although the resin interlayer is chemically bonded, its viscosity is more affected by the change of temperature which is indicated also by the increase in ultimate deflection of laminated glass. The reduction of the flow activation energy [12] in case of EVA interlayer reduces the degree of temperature sensitivity, hence, reduces the change of viscosity due to temperature change, which affects the bending characteristics of laminated glass.

The ultimate force decreases and the ultimate deflection increases significant in case of theoretical delamination, which is presented by non-bonded glass layers. The estimations on delamination temperature [9] are presented in the following chapter. The ratio of standard deviation and the average is the highest in case of non-bonded layers. The change of the ratio is less affected with change of temperature in case of EVA interlayer, but increases with increase of number of glass layers. 


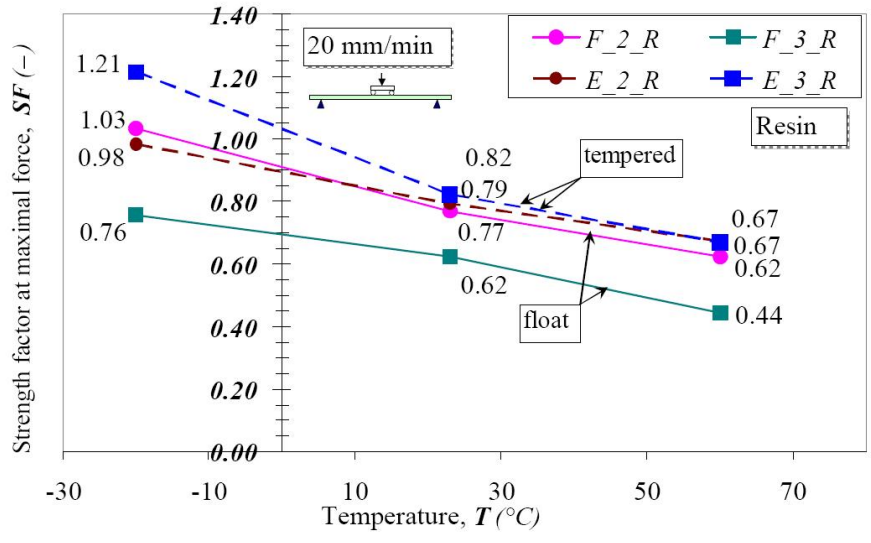

(a)

Fig. 7. Ratio of maximal force of laminated glass (consisting of two or three glass layers) to single glass layer with equivalent thickness at maximal force

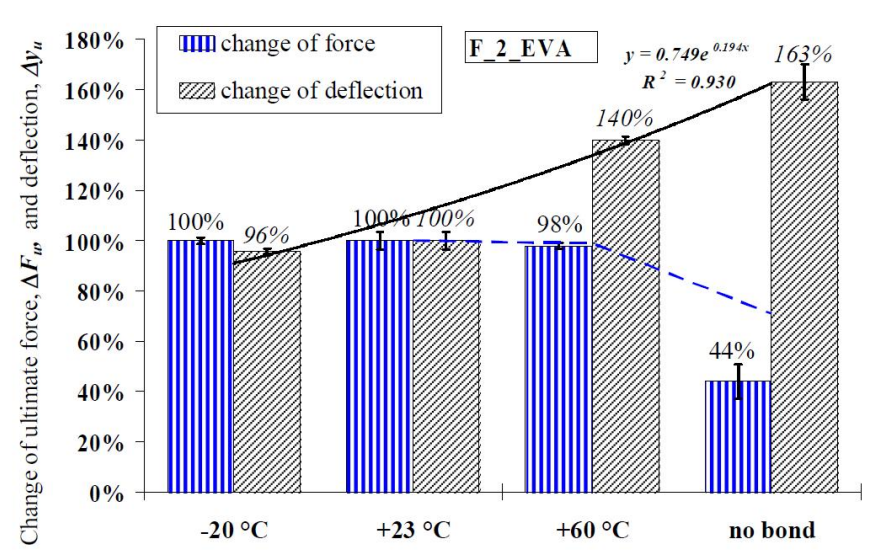

(a)

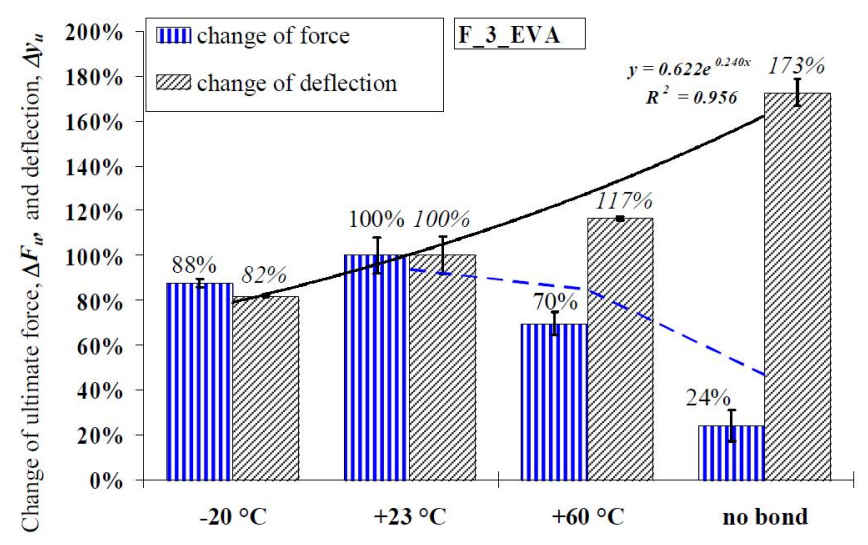

(c)

Fig. 8. (a) Change of ultimate force and deflection of laminated glass consisting of two float glass layers and EVA interlayer (symbol: F_2_EVA). (b) Change of ultimate force and deflection of laminated glass consisting of two tempered glass layers and EVA interlayer (symbol: E_2_EVA). (c) Change of

\subsection{Flexural stiffness of laminated glasses at different tem- peratures}

The problem for laminated glass calculations is usually the unknown shear stiffness and the shear modulus, $G$, of the interlayer material, because of the time dependency of the loads and because temperature can modify the shear modulus. Deflections

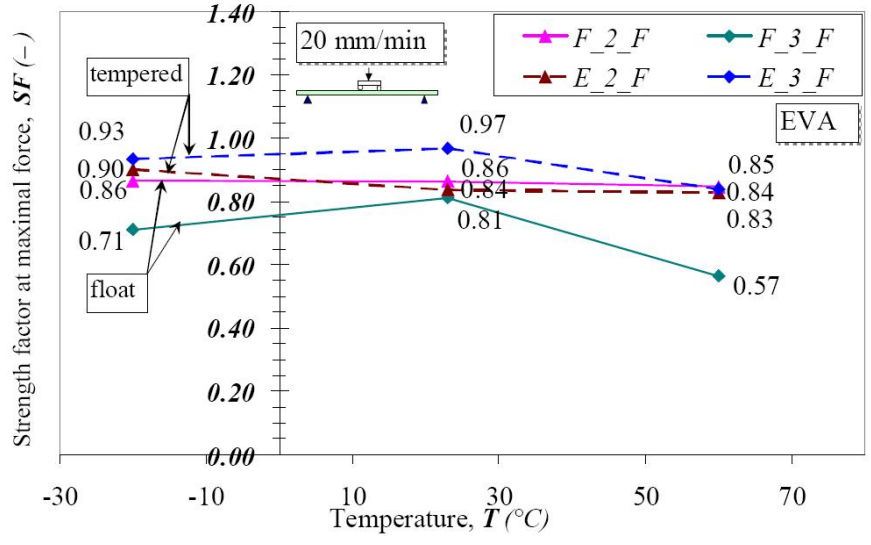

(b)

(a) laminated with resin (_R) or (b) with EVA (_F) at temperatures of $-20{ }^{\circ} \mathrm{C}$, $+23{ }^{\circ} \mathrm{C}$ and $+60{ }^{\circ} \mathrm{C}$

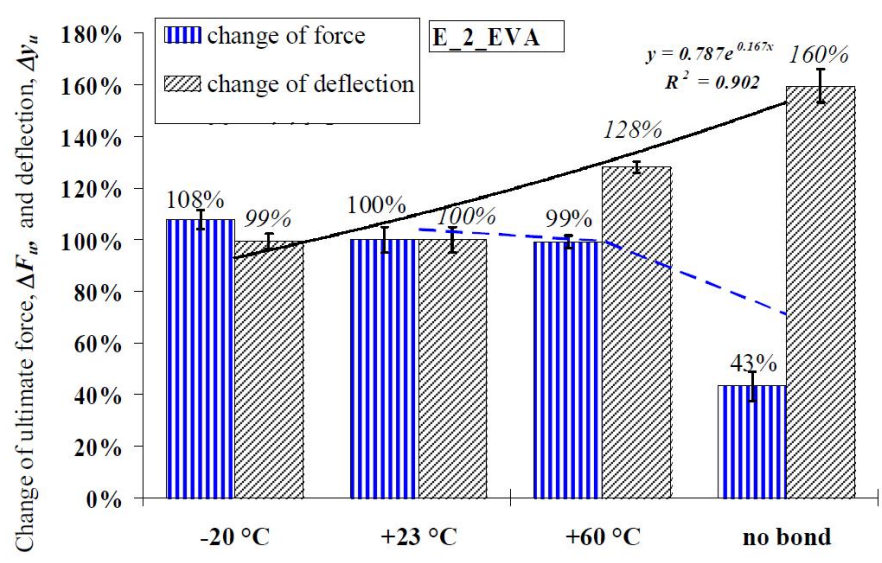

(b)

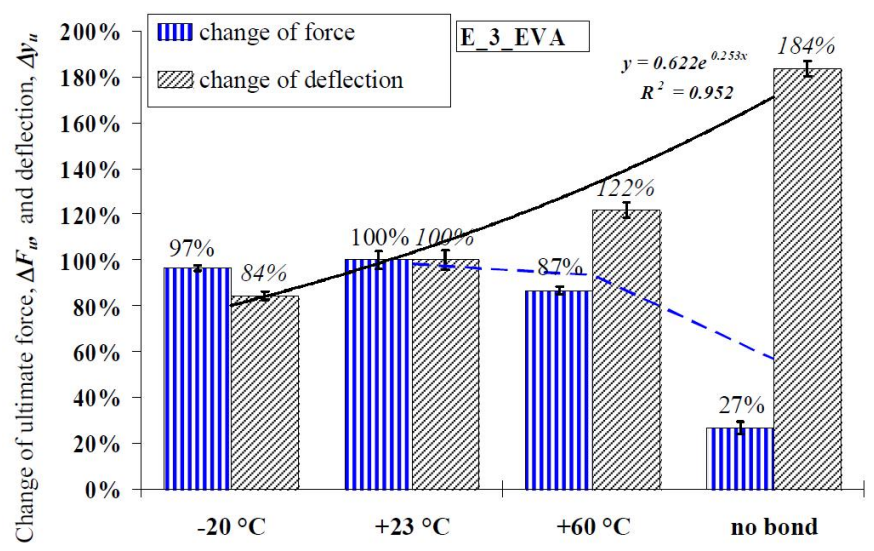

(d)

ultimate force and deflection of laminated glass consisting of three float glass layers and EVA interlayer (symbol: F_3_EVA). (d) Change of ultimate force and deflection of laminated glass consisting of three tempered glass layers and EVA interlayer (symbol: E_3_EVA).

can increase with increase of temperature when the interlayer material softens. Therefore, an appropriate interlayer material should be selected which is able to transfer forces at the service temperature of laminated glasses [9]. By determining the exposure class of laminated glasses, its load bearing resistance and its temperature sensitivity should be taken into account (by 


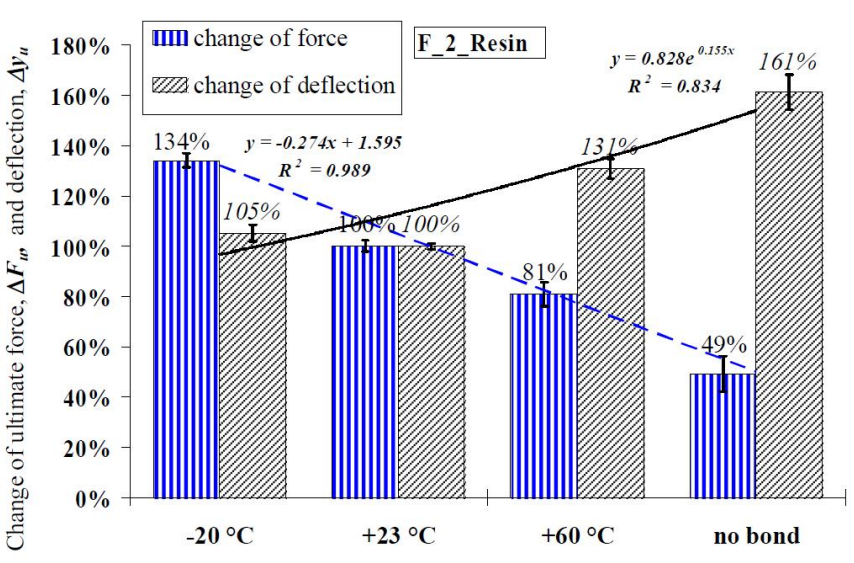

(a)

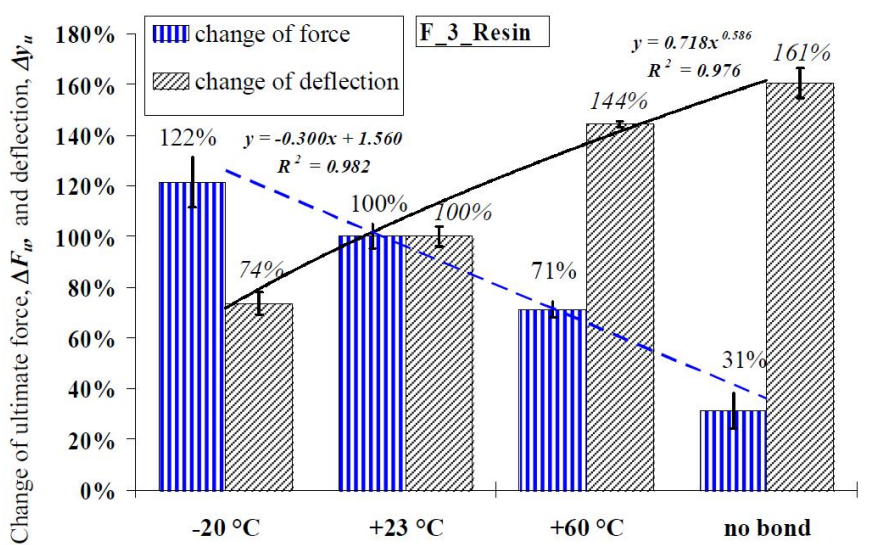

(c)

Fig. 9. (a) Change of ultimate force and deflection of laminated glass consisting of two float glass layers and resin interlayer (symbol: F_2_Resin). (b) Change of ultimate force and deflection of laminated glass consisting of two tempered glass layers and resin interlayer (symbol: E_2_ Resin). (c) Change of

creating different classes for them).

The author proposes to use the flexural stiffness $\left(D_{f l}\right)$ of laminated glasses to characterise the bending characteristics, which is dependent on the visco-elastic properties of interlayer materials:

$$
D_{f l}(t, T)=E I_{f l}(t, T)\left[N m^{2}\right]
$$

where $E I_{f l}$ is the flexural stiffness calculated with 2 in the case of four-point bending.

$$
E I_{f l}=\frac{F}{16 y}\left[\frac{L_{S}^{3}}{3}+\frac{L_{b}^{3}}{6}-\frac{L_{S} L_{b}^{2}}{2}\right]
$$

The flexural stiffness of laminated glass types was calculated by using measured average values of maximal forces (at fracture of the first glass layer) at temperatures of $-20{ }^{\circ} \mathrm{C},+23{ }^{\circ} \mathrm{C}$ and $+60{ }^{\circ} \mathrm{C}$. The flexural stiffness of the overall laminate is influenced by temperature. With increasing temperature, the flexural stiffness decreases. The tendency of decrease of flexural stiffness at different temperatures is influenced by the type of interlayer material.

The flexural stiffness affected by temperature is indicated for resin and EVA interlayer materials in Fig. 10 and Fig. 11

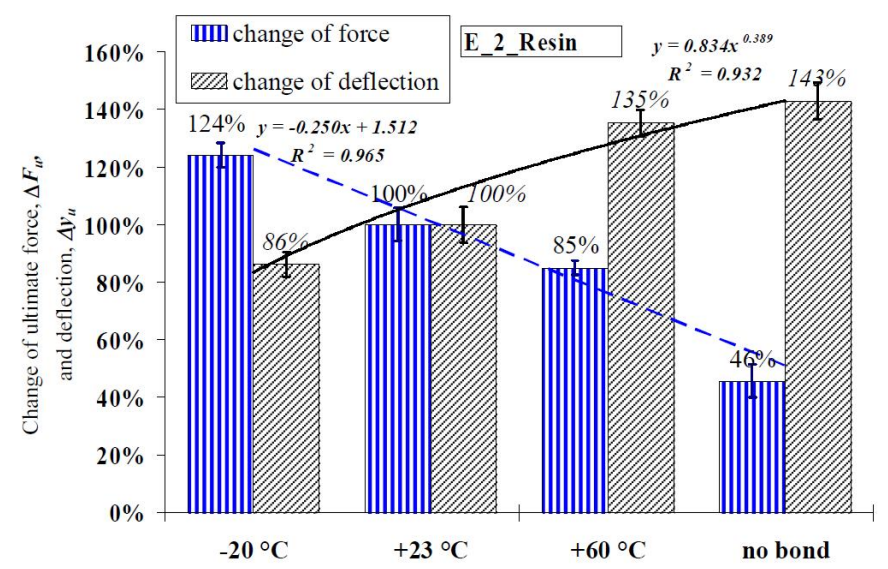

(b)

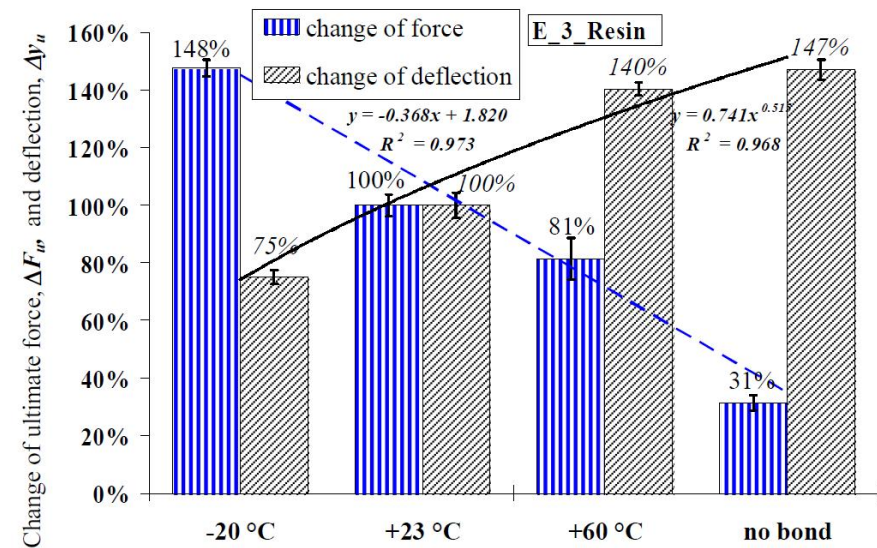

(d)

ultimate force and deflection of laminated glass consisting of three float glass layers and resin interlayer (symbol: F_3_Resin). (d) Change of ultimate force and deflection of laminated glass consisting of three tempered glass layers and resin interlayer (symbol: E_3_Resin).

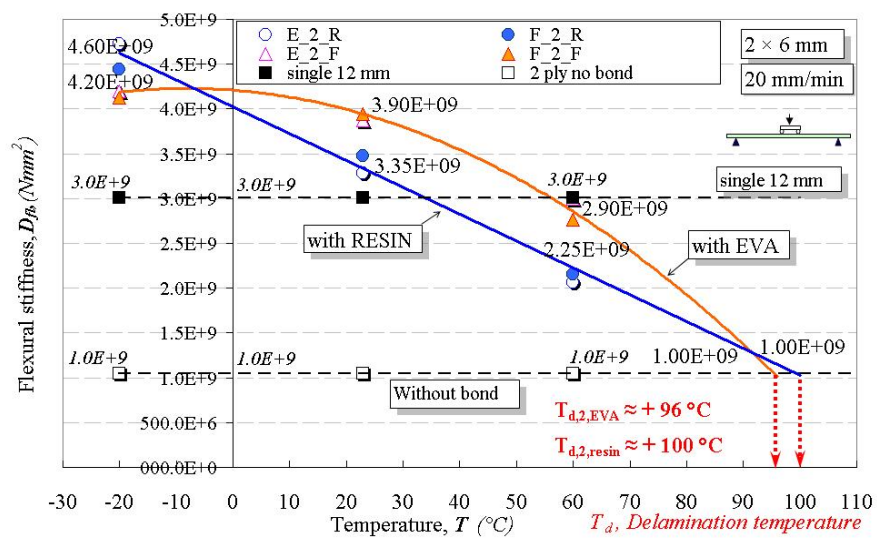

Fig. 10. Flexural stiffness vs. temperature of laminated glasses consisting of $2 \times 6 \mathrm{~mm}$ float $\left(\mathrm{F}_{-}\right)$or tempered $\left(\mathrm{E}_{-}\right)$glass layers with use of resin (_R) and EVA foil (_F) interlayer materials.

The flexural stiffness decreases linearly if temperature decreases for resin and decreases polynomially for EVA interlayer material in the case of safety and non safety laminated glasses. In Fig. 10 and Fig. 11 laminated glass without bonded layers is also indicated. Results of laminated glass without bonded lay- 


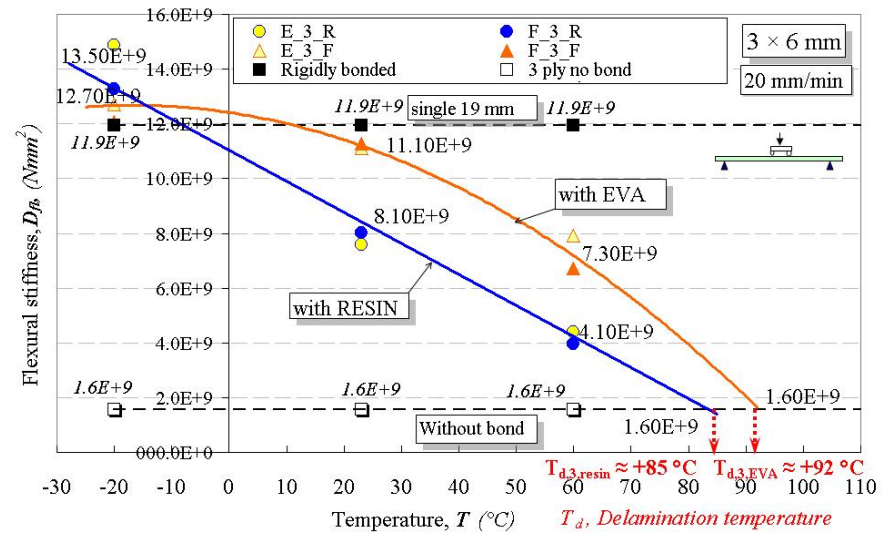

Fig. 11. Flexural stiffness vs. temperature of laminated glasses consisting of $3 \times 6 \mathrm{~mm}$ float $\left(\mathrm{F}_{-}\right)$or tempered $\left(\mathrm{E}_{-}\right)$glass layers with use of resin $\left({ }_{-} \mathrm{R}\right)$ and EVA foil (_F) interlayer materials.

ers indicate the lower limit of flexural stiffness. Therefore, the temperature can be predicted when the interlayer is not able to transfer shear forces between the glass layers. The author proposes the definition of delamination temperature, $T_{d}$, of laminated glasses. The delamination temperature is influenced by the type of applied interlayer material. Delamination of laminated glass can happen due to chemical reactions, e.g. aging of interlayer material, or due to physical phenomenon, e.g. considerably decrease of bond strength (change of viscosity or adhesion of interlayer material) [9]. The delamination temperature is about $100{ }^{\circ} \mathrm{C}$ in the case of resin interlayer laminated glasses consisting of two glass layers. The delamination temperature is about $96{ }^{\circ} \mathrm{C}$ in the case of EVA interlayer laminated glasses consisting of two glass layers. The applied loading rate was 20 $\mathrm{mm} / \mathrm{min}$. In the case of increase of number of glass layers in laminated glass or with the increase of interlayer thicknesses, the delamination temperature decreases. The decrease of the delamination temperature is $4{ }^{\circ} \mathrm{C}$ in the case of EVA and $15{ }^{\circ} \mathrm{C}$ in the case of resin interlayer material from the increase of the number of glass layers from two to three in laminated glass. The delamination temperature is influenced by the rate and type of loading (e.g. static or cyclic), hence, the time and temperature influence on physical properties of polymers [12]. Therefore, further investigations are needed, especially in the case of load bearing glasses.

The upper limit of the flexural stiffness of laminated glass can be indicated by the equivalent monolithic single layer glasses. In this case, the upper limit of flexural stiffness of single glass layers with thickness of $12 \mathrm{~mm}$ (Fig. 10) and $19 \mathrm{~mm}$ (Fig. 11) was exceeded by laminated glasses at those service temperatures where the appropriate bond is ensured and the stiffness of laminated glasses increased due to relatively stiff interlayer material (see also Fig. 7).

Fig. 12 indicates the flexural stiffness vs. ratio of total interlayer thickness to total thickness of laminated glass. The higher values of $D_{f l}$ in Fig. 12 indicate higher flexural stiffness and stiffer bond. The shift of the values (points) compared to a ref- erence temperature (e.g. $+23{ }^{\circ} \mathrm{C}$ ) indicates the temperature sensitivity of the interlayer material.

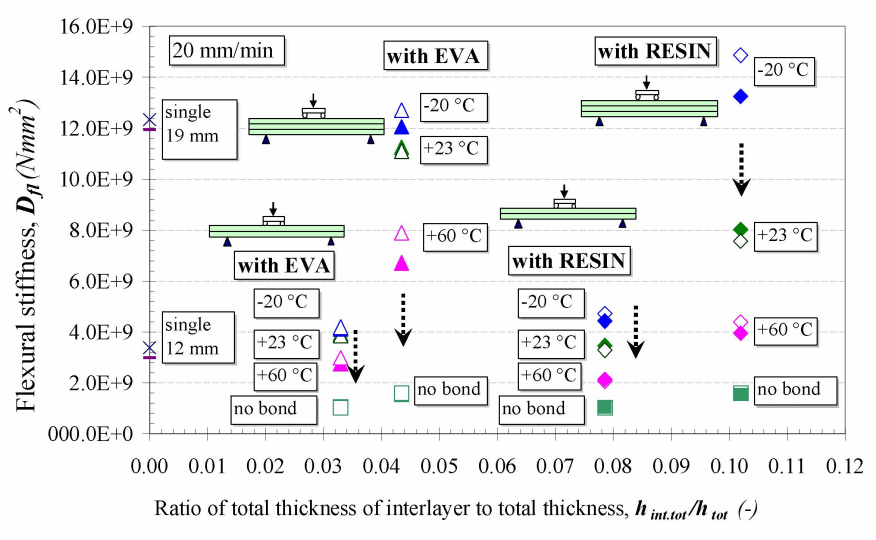

Fig. 12. Flexural stiffness vs. ratio of thickness of interlayer material to total thickness. Squares indicate laminated glasses without bonded layers. Triangles indicate laminated glasses with EVA interlayer and diamonds indicate laminated glasses with resin interlayer, respectively. Empty squares, triangles or diamonds indicate laminated glasses consisting of tempered glass layers. Solid squares, triangles or diamonds indicate laminated glasses consisting of float glass layers.

Fig. 12 can properly indicate the temperature or time dependent behaviour of laminated glasses. The bottom values (squares) in Fig. 12 indicate laminated glasses without use of interlayer material. Therefore, with increasing temperature, the shifting of the points tends in the direction of these values. Fig. 12 indicates that resin laminated glasses (both tempered and float) are more temperature sensitive than EVA laminated glasses. With the observation of the shift tendency of the values (points), the durability of laminated glasses can be also predicted.

\subsection{Calculations of temperature dependent flexural stiff- ness of laminated glasses}

The aim of present study was to define the flexural stiffness of laminated glass as a function of temperature, considering even large deflections as well as thick plastic interlayer.

The primary interlayer property that influences the strength and deflection is the shear stiffness, in the case of small deflections.

[2] defined a coupling parameter, $\kappa$, which represents the bond of the glass layers to the interlayer, Eq. (4). Fig. 13 indicates the three-point bending tests by [2]. Concentrated load $\mathrm{F}=20 \mathrm{~N}$ was applied at the mid-span of the beam (span $L_{s}=400 \mathrm{~mm}$, width $\mathrm{b}=30 \mathrm{~mm}$ ) which consists of laminated glass ( $4 \mathrm{~mm}$ glass / $0.76 \mathrm{~mm}$ PVB / $4 \mathrm{~mm}$ glass), where, $h$ is the thickness of the glass layer, $h_{\text {int }}$ is the thickness of the interlayer.
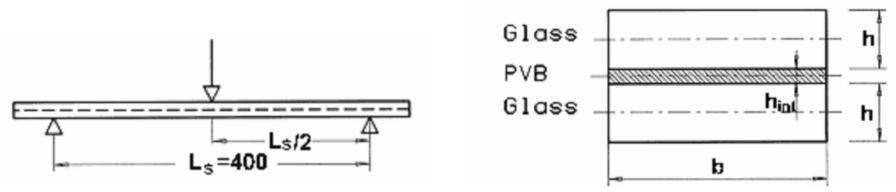

Fig. 13. Three-point bending tests by [2]. 
The centre deflection can be calculated by Eq. (3), with consideration of bending [2]:

$$
y=\frac{F L^{3}}{48(E I)_{\text {beam }}}
$$

where, $E$ and $I$ are the Young's modulus and the moment of inertia of the beam, respectively. The moments of inertia of the glass plates, $I_{g}$, of the interlayer, $I_{\text {int }}$ and the coupling term, $I_{c}$, contribute to the total amount of the moment of inertia, $I$. The cross section of the beam is shown in Fig. 13

$$
\begin{gathered}
(E I)_{\text {beam }}=E_{g} I_{g}+E_{\mathrm{int}} I_{\mathrm{int}}+E_{c} I_{c} \approx E_{g} I_{g}+E_{c} I_{c} \\
I_{g}=2 b \frac{h^{3}}{12}, \quad I_{\mathrm{int}}=b \frac{h_{\mathrm{int}}^{3}}{12}, \quad I_{c}=\kappa b h\left(h+h_{\mathrm{int}}\right)^{2}
\end{gathered}
$$

In the case of $I_{\text {int }}<<I_{g}$, the moment of inertia of the interlayer can be neglected. The value of parameter $\kappa$ should be between $0 \leq \kappa \leq 1$. Parameters $\kappa$ and $E_{c}$ were determined from experiments and can be dependent on time and temperature, $\kappa(T, t)$. In the case of $\kappa=1$ the total moment of inertia is equal to the moment of inertia of a monolithic beam with the thickness $h_{\text {beam }}=2 h+h_{\text {int }}$. In the case of $\kappa=0$ the glass layers are not bonded and $I=I_{g}$.

The author suggests the modification of Eq. (4) given earlier by [2]:

$$
(E I)_{T, \text { service }}=\left(E_{g} I_{g}\right)_{T_{d}}+\kappa\left(E_{c} I_{c}\right)
$$

and

$$
\begin{aligned}
& -E_{c} I_{c}=(E I)_{T_{g}}-E_{g} I_{g} \\
& -E_{g} I_{g}=70000 \frac{b h_{e f f, T_{d}}^{3}}{12} \\
& -h_{e f f, T_{d}}=\sqrt[3]{\sum_{i=1}^{n} h_{i}^{3}}
\end{aligned}
$$

where

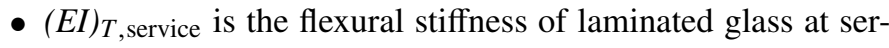
vice temperature, Eq. (7);

- $\left(E_{g} I_{g}\right)_{T d}$ is the flexural stiffness when delamination occurs at delamination temperature, $T_{d}$, and can be calculated with use of effective thickness of non bonded glass layers. In the case of non bonded glass layers $h=h_{\text {eff,Td }}$ should be applied according to Eq. (10), where, $n$ is the number of glass layers and $h_{i}$ is the thickness of $i^{\text {th }}$ single glass layer;

- $\kappa$ is the coupling term of modified flexural stiffness $\left(E_{c} I_{c}\right)$. The value of parameter $\kappa$ should be between 0 and 1 . In the case of $\kappa=1$, the stiffness of laminated glass can be calculated with the sandwich model [17] at glass transition temperature, $T_{g}$. In the case of $\kappa=0$, the glass layers are not bonded or delamination occurred. Parameter $\kappa(T, t)$ can be experimentally determined and is dependent on temperature or (and) time (Fig. 15).
- $(E I)_{T g}$ is the flexural stiffness of laminated glass at the glass transition temperature, $T_{g}$, of the interlayer material, where the sandwich model (Fig. 14) can be applied only when the interlayer is in a glassy state;

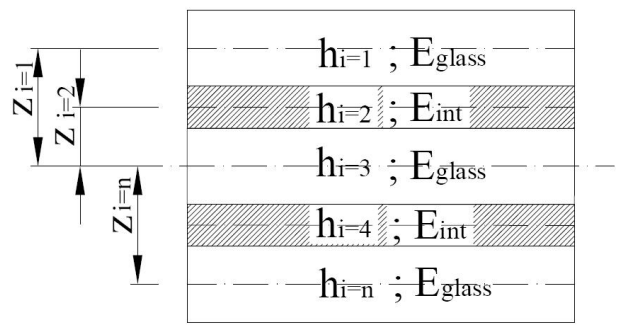

Fig. 14. Sandwich model, where $h_{i}$ is the thickness of the $i^{\text {th }}$ layer in sandwich [9].

$$
\sum_{i=1}^{n} z_{i} E_{i} h_{i}=0
$$

- the effective thickness of layered sandwich at glass transition temperature, $T_{g}$, is:

$$
h_{e f f, T_{g}}=\sqrt{\frac{\sum_{i=1}^{n} E_{i} h_{i}\left(h_{i}^{2}+12 z_{i}^{2}\right)}{\sum_{i=1}^{n} E_{i} h_{i}}}
$$

- the effective Young's modulus of layered sandwich at glass transition temperature, $T_{g}$, is:

$$
E_{e f f, T_{g}}=\frac{\sum_{i=1}^{n} E_{i} h_{i}}{h_{e f f, T_{g}}}
$$

The value of the glass transition temperature, $T_{g}$, and the value of HDT (Heat Distortion Temperature) of the interlayer material should be taken into account and the delamination temperature, $T_{d}$, should be determined experimentally, where further influencing factors can be taken into account, e.g. TTS (Time-Temperature Superposition). Therefore, delamination temperature, $T_{d}$, is not equal to the melting temperature, $T_{m}$, of the interlayer material, but $T_{m}$, also influences $T_{d}$.

The temperature dependent behaviour of laminated glass should be studied on the whole laminated material. It is not enough to study the temperature dependent behaviour of the interlayer material. Therefore, based on the laboratory results the coupling parameter, $\kappa$, was determined directly for laminated glasses (Fig. 15).

With the coupling parameter, $\kappa$, the flexural stiffness of resin and EVA foil laminated glasses at service temperature range can be determined. Further investigations should be done on different types of interlayer materials. In the case of known

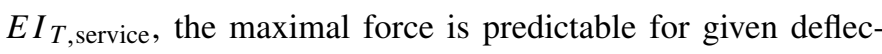
tions e.g. $y_{\text {allowed }}=L_{S} / 200$.

Table 1 and 2 summarise the data for calculating the coupling parameter, $\kappa$, for tested types of laminated glasses. 


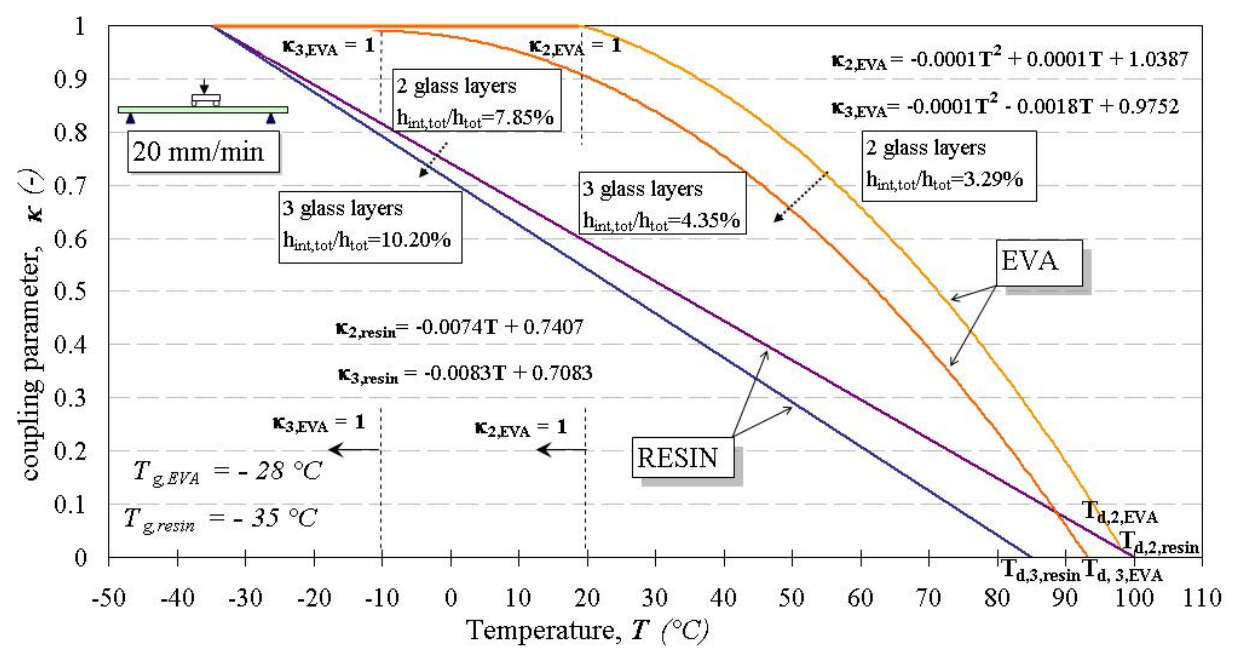

Fig. 15. Coupling parameter, $\kappa$, of resin and EVA interlayer materials in temperature range from glass transition temperatures, $T_{g}$, to delamination tem-

peratures, $T_{d}$, of laminated glasses consisting of two or three glass layers.

Tab. 2. Calculation of coupling parameter, $\kappa$ sgt service temperature,

thickness and with EVA or resin interlayer material.

$T_{\text {service }}$, of laminated glasses consisting of two or three glass layers with $6 \mathrm{~mm}$

\begin{tabular}{|c|c|c|c|}
\hline Type of interlayer material & $\begin{array}{l}\text { Number of glass layers, } \mathrm{n} \\
\text { [pcs] }\end{array}$ & $\begin{array}{c}\text { Service temperature ranges, } \\
T_{\text {service }}\left[{ }^{\circ} \mathrm{C}\right]\end{array}$ & $\begin{array}{l}\text { Calculation of coupling } \\
\text { parameter, } \kappa\end{array}$ \\
\hline \multirow{4}{*}{ EVA } & \multirow{2}{*}{2} & $T_{g} \leq T \leq+20^{\circ} \mathrm{C}$ & 1 \\
\hline & & $+20^{\circ} \mathrm{C} \leq T \leq T_{d}$ & $-0.0001 T^{2}+0.0001 T+1.0387$ \\
\hline & \multirow{2}{*}{3} & $T_{g} \leq T \leq-10{ }^{\circ} \mathrm{C}$ & 1 \\
\hline & & $-10^{\circ} \mathrm{C} \leq T \leq T_{d}$ & $-0.0001 T^{2}+0.0018 T+0.9752$ \\
\hline \multirow{2}{*}{ Resin } & 2 & $T_{g} \leq T \leq T_{d}$ & $-0.0074 T+0.7407$ \\
\hline & 3 & $T_{g} \leq T \leq T_{d}$ & $-0.0083 T+0.7083$ \\
\hline
\end{tabular}

Tab. 1. Glass transition and delamination temperatures of laminated glasses consisting of two or three glass layers with $6 \mathrm{~mm}$ thickness and with use of EVA or resin interlayer material.

\begin{tabular}{cccc}
\hline $\begin{array}{c}\text { Type of } \\
\text { interlayer } \\
\text { material }\end{array}$ & $\begin{array}{c}\text { Number of } \\
\text { glass layers, } n \\
\mathrm{pcs}\end{array}$ & $\begin{array}{c}\text { Glass transition } \\
\text { temperature, } T_{g} \\
{ }^{\circ} \mathrm{C}\end{array}$ & $\begin{array}{c}\text { Delamination } \\
\text { temperature, } T_{d} \\
{ }^{\circ} \mathrm{C}\end{array}$ \\
\hline \multirow{2}{*}{ EVA } & 2 & -28 & +96 \\
\hline Resin & 3 & -28 & +92 \\
\hline & 2 & -35 & +100 \\
\hline
\end{tabular}

Tables 2 indicates the equations to calculate the coupling parameter in service temperature ranges between defined temperatures. For determination of glass transition and delamination temperatures Table 1 should be used.

With increasing temperature, the shear stiffness rapidly decreases and creep becomes more significant. In the so-called accelerated testing method with increase of temperature, the effect of creep on load bearing capacity can be estimated. The Young's modulus $\left(E_{t 0}\right)$ depending on time or load, e.g. for constant loads, is [18]:

$$
E_{t 0}=\frac{E_{0}}{1+\varphi}
$$

where, $E_{0}$ is Young's Modulus for short time loads and $\varphi$ is the creep parameter. Therefore, the effect of time and temperature on creep parameter should be investigated as future extension of this study.

Relaxation is also a well-known phenomenon of plastic materials, which influences the bending characteristics of laminated glass. The aging of the interlayer material acts on its bond capacity, etc., therefore, these effects can be defined in the coupling parameter, $\kappa$. In the case of increasing temperature or lifetime predictions on the strength of laminated glass, the temperature dependent flexural stiffness ( $D_{f l, T \text {, service }}$ ) should be studied. Thereby, the influence of temperature on bond capacity can be taken into account and also the membrane effect [7] by increasing deflections.

The bond capacity of an interlayer material is important. Therefore, further interlayer materials have to be studied and developed for different kinds of glazing applications, especially in the case of load bearing glasses. To take into account the service temperature and loading condition, e.g. loading rate, the exposure class should be determined on safety basis.

With known thermo-mechanical behaviour and exposure class, the appropriate laminated glass at the "service" or application temperature can be chosen, therefore, the load bearing 
capacity and durability of it can be safer determined. The appropriate interlayer material should be chosen for the actual exposure class [9]. To the exposure classes of a laminated glass also the interlayer properties at least with glass transition temperature, $T_{g}$, and delamination temperature, $T_{d}$, as well as with thermo-mechanical behaviour should be investigated.

\section{Conclusions}

Based on the results of the laboratory tests with safety and non safety laminated glasses, the following conclusions can be drawn for the flexural stiffness of laminated glasses:

- The type of the interlayer materials should be carefully selected of load-bearing glass applications.

One which is able to transfer forces in application (service) temperatures ranges.

One which is able to transfer forces in application (service) temperatures ranges.

- The decrease in flexural stiffness at different temperatures is influenced by the type of interlayer material. The temperature influence on flexural stiffness is being indicated for resin and EVA interlayer materials. The flexural stiffness decreases linearly in the case of resin and it decreases polynomially in the case of EVA interlayer material, both for safety and non safety laminated glasses.

- Based on the laboratory results the definition of delamination temperature, $T_{d}$ of laminated glasses was introduced. In the case of increase of the number of glass layers in laminated glass or increase of interlayer thickness, the delamination temperature decreases.

- The author presented the flexural stiffness vs. ratio of total interlayer thickness to total thickness of laminated glass at different temperatures. The shift of the values (points) compared to a reference temperature (e.g. $+23{ }^{\circ} \mathrm{C}$ ) indicates the temperature sensitivity of the interlayer material. With the observation of the shift tendency of the values, the durability of laminated glasses can be also predicted.

- Based on the laboratory results the author has modified the definition of coupling parameter, $\kappa$, which was originally defined by [2]. The coupling parameter, $\kappa$, was determined directly for laminated glasses with resin and EVA interlayer materials.

- The composite effect pronounced by the shear resistance of the interlayer material [1] should be neglected, especially under higher temperatures and (or) long-term loads, and when the interlayer tends to creep. In the case of increasing temperature or lifetime predictions on the load bearing capacity of laminated glass, the temperature dependent flexural stiffness $\left(D_{f l, T, \text { service }}\right)$ should be studied.

- The exposure class of laminated glass should be determined according to the application (service) temperature range.
Therefore, the testing temperature should be selected according to the exposure temperature. Especially for outdoor applications the tests carried out at room temperature should be extended on further testing temperatures. For safety basis the upper and lower load-bearing capacity should be determined with taking into account the environmental conditions.

\section{References}

1 Wölfel E, Compliant bond as approximate solution and application possibilities of it, - Nachgiebiger Verbund eine NäherungslĂśsung und deren Anwendungsmöglichkeiten, Stahlbau (1987), no. 6, 173-180.

2 Krüger G, Temperature effects on the structural behaviour of laminated safety glass, Otto-Graf-Journal (1998), no. 9, 153-163.

3 Savineau G F, Laminated architectural glass test performance criteria and reality, 1999. Glass processing days 1999.

4 Pankhardt K, Investigation on load bearing capacity of glass panes, Periodica Polytechnica, Civil engineering 52 (2008), no. 2, 73-82, DOI 10.3311/pp.ci.2008-2.03.

5 Norville H S, The effect of interlayer thickness on laminated glass strength, 1997. Glass processing days 1997.

6 Behr R A, Minor J E, Linden M P, Vallabhan C V G, Laminated glass units under uniform lateral pressure, Journal of structural Engineering 111 (1985), no. 5, 1037-1050.

7 Vallabhan G, Minor J, Nagalla S, Stresses in layered glass units and monolithic glass plates, Journal of structural Engineering 113 (1987), no. 1, 36-43.

8 Weibull W, A statistical representation of fatigue failures in solids, Elandes Boktryckeri Aktiebolag, Göteborg, Sweden, 1949.

9 Pankhardt K, Balázs L Gy, Temperature dependent load bearing capacity of laminated glass panes, Periodica Polytechnica, Civil engineering (2010). accepted paper, in print.

10 Minor J E, Windborne debris and the building envelope, Journal of Wind Engineering and Industrial Aerodynamics 53 (1994), no. 1-2, 207-227, DOI 10.1016/0167-6105(94)90027-2.

11 Netherton M D, Stewart M G, The effects of explosive blast load variability on safety hazard and damage risks for monolithic window glazing, Seventh International Conference on Shock and Impact Loads on Structures, 2009 pp. 1346-1354, DOI 10.1016/j.ijimpeng.2009.02.009.

12 Brandrup J, Immergut E H, Grulke E A, Polymer Handbook 1-2, WileyInterscience, New York, U.S.A., 1989. fourth ed.

13 EN 1288-3: 2000, Glass in Building - Determination of the bending strength of glass - Part 3: Test with specimen supported at two points (four-point bending), CEN, Brussels, 2000.

14 ISO 48:1994, Rubber, vulcanised or thermoplastic - Determination of hardness (hardness between 10 IRHD and 100 IRHD), TC45/SC2, ISO, 1994.

15 Pankhardt K, Load bearing glass structures, Periodica Polytechnica, Civil engineering 48 (2004), no. 1-2, 157-172.

16 Kadri I, Lambrechts P, Cornelis A, Adding freedom to contemporary architecture with resin glass laminates, 2003. Poster 6.

17 Hegedűs I, Building material practicum - Építóanyag praktikum, Mûszaki könyvkiadó, Budapest, Hungary, 1983. Strength and deformation characteristics of sandwich structures, - Szendvicsszerkezetek szilárdsági és alakváltozási jellemzői.

18 Palotás L, Balázs Gy, Materials' science of engineering structures 3. - Concrete-Mortar-Ceramic-Plastic, Mérnöki szerkezetek anyagtana 3., Beton-Habarcs-Kerámia-Múanyag, Akadémiai Kiadó, Budapest, Hungary, 1980. 